\title{
Blockchain in Corporate Finance: A Review of Use-Case, Opportunities and Risks
}

\author{
Gianfranco Marotta ${ }^{1}$ and Cam-Duc $\mathrm{Au}^{2 *}$
}

${ }^{1}$ FOM University of Applied Sciences for Economics and Management, Germany; PPA Business School - École de Commerce et de Management, France

${ }^{2}$ FOM University of Applied Sciences for Economics and Management, Germany; Masaryk University - Faculty of Finance, Czech Republic

\begin{tabular}{|c|c|}
\hline ARTICLE INFO & ABSTRACT \\
\hline $\begin{array}{l}\text { Keywords: } \\
\text { Blockchain } \\
\text { Disruption } \\
\text { Innovation } \\
\text { Digitization } \\
\text { Cryptocurrencies }\end{array}$ & $\begin{array}{l}\text { In the era of the digital revolution, organizations are surrounded by } \\
\text { disruptive technologies and find themselves constantly in the middle of } \\
\text { change processes. In recent years, blockchain technology has evolved } \\
\text { tremendously, and in the future, it may fundamentally influence and change } \\
\text { the finance and accounting domain of the early } 21^{\text {st }} \text { century. Originally the } \\
\text { blockchain technology was created only as technology to introduce the } \\
\text { cryptocurrency Bitcoin, however by now the blockchain is considered by } \\
\text { experts as a major innovation beyond its initial scope. } \\
\text { In light of these changing circumstances, innovative opportunities, as well } \\
\text { as new challenges, arise. This creates many questions and academic } \\
\text { debates among researchers all over the globe as to which business models } \\
\text { and functions in the financial sector may become obsolete or where to } \\
\text { streamline and enhance processes through blockchain applications. } \\
\text { The paper addresses the research question to what extent the blockchain } \\
\text { technology is capable of changing well-known business processes and } \\
\text { finance functions within companies. In doing so, it shows the } \\
\text { opportunities and challenges, which are based on an extensive literature- } \\
\text { review by the authors. The paper presents current use cases on market and } \\
\text { finishes with an outlook on the future potential of blockchain. }\end{array}$ \\
\hline
\end{tabular}

\section{Introduction- Disruptive Technologies}

\subsection{Problem Statement \& Research Objective}

In the era of the digital revolution, organizations are surrounded by disruptive technologies and find themselves constantly in the middle of change processes. In recent years, blockchain technology has evolved tremendously, and in the future, it may fundamentally influence and change the finance and accounting domain of the early $21^{\text {st }}$ century. Originally the blockchain

* Corresponding author E-mail address: cam-duc.au@fom-net.de Applied Research in Management and Economics, 4(1), 1-12. https://doi.org/10.33422/ijarme.v4i1.486

(C) The Author(s). 2021 Open Access. This article is distributed under the terms of the Creative Commons Attribution 4.0 International License, which permits unrestricted use, distribution, and redistribution in any medium, provided that the original author(s) and source are credited. 
technology was created only as technology to introduce the cryptocurrency Bitcoin, however by now the blockchain is considered by experts as a major innovation beyond its initial scope (see Swan, 2015; Underwood, 2016; Iansiti \& Lakhani, 2017; Tapscott \& Tapscott, 2017; Nordgren et al., 2019).

In light of these changing circumstances, innovative opportunities, as well as new challenges, arise. This creates many questions and debates as to which business models and functions in the financial sector may become obsolete or where to streamline and enhance processes through blockchain applications. In this context, the following term paper offers a review on use-cases of the blockchain technology in the field of corporate finance. The research questions of interest can be summarized as follows:

"How does the blockchain technology change well-known business processes and finance functions and consequently, what opportunities and challenges can be anticipated?"

\subsection{Structure \& Methodology}

This paper is divided into four sections with respective sub-sections (see Figure 1). The first Section covers the problem statement, research objective, and description of the scope. Following this, Section 2 offers a short review on the theoretical basics of the blockchain technology and its "plug-in" function called "smart contracts". In Section 3 different application areas of the blockchain technology are presented as a status quo review and to gain inspiration for new ideas. Building on this, blockchain use-cases in finance are discussed with regard to the arising opportunities and challenges. Section 4 covers a conclusion and an outlook next to a short recommendation regarding future research.

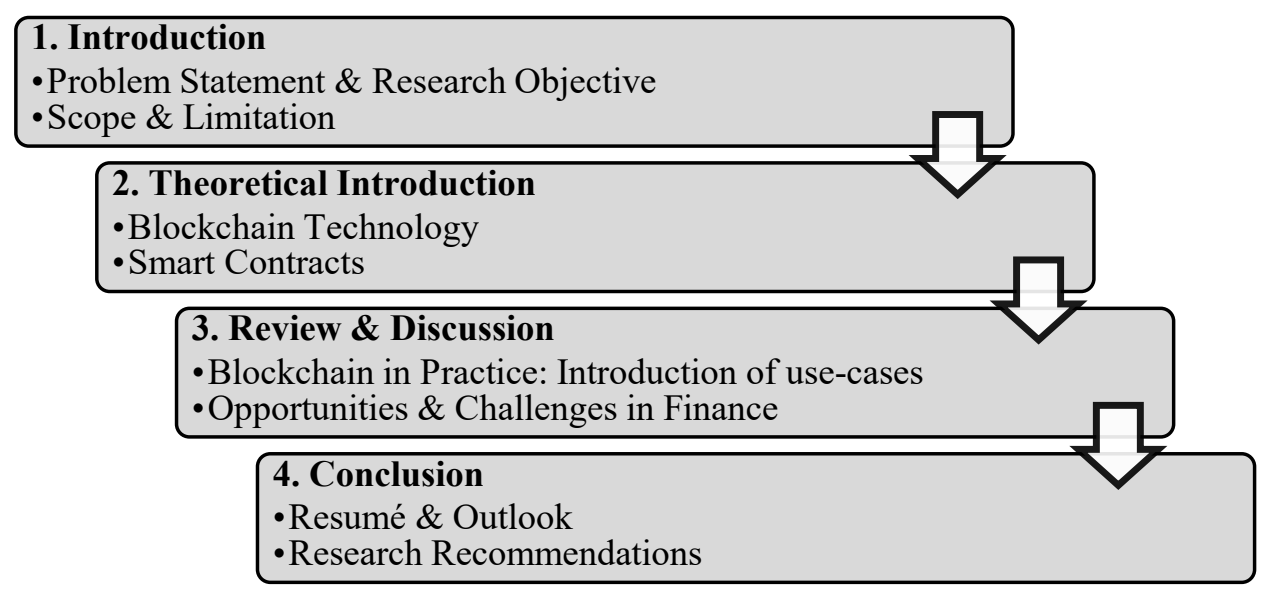

Figure 1. Summarized Paper Structure

Source: Own presentation

This paper is a result of literature studies in which other authors' perspectives and analyses have been used and critically analyzed. The underlying literature consists of various journals and internet sources, which results from the topicality of this topic. The propositions made in this paper should be further investigated with empirical verification and critical reflections. 


\section{Theoretical Basics - New Technologies in Corporate Finance}

\subsection{Status-Quo Review on Blockchain}

The blockchain technology shows an impressive debut, only in 2008 the technology emerged with the introduction of the crypto-currency Bitcoin (BTC) of which the origin is a whitepaper published in 2008 under the pseudonym "Satoshi Nakamoto" with the title: "Bitcoin: A Peer-to-Peer Electronic Cash System" (Nakamoto, 2008 in Nordgren et al. 2019, p. 49). In July 2016, blockchain was already at the top of the peak of Gartner's hype curve, located between "smart robotics" and the "connected home" and in 2017, the blockchain and distributed ledgers technology was listed as a "Top ten strategic technology trend" (Panetta, 2017 in O'Leary, 2017, p. 138).

In short, blockchain is an open, distributed data structure that can efficiently record transactions. All executed transactions are stored in blocks, whereby each block refers to the previous one. In order to capture new transactions, further blocks must be created. The creation is the result of a mining process, whereby new blocks are added to the blockchain in a linear and chronological order. Thereby, a counterfeit-proof chain is created (Hacker \& Thomale, 2017, p. 8; Treleaven et al., 2017, p. 14; Rauscher \& Cupic 2018 p. 5 et seqq.; Gupta \& Sadoghi, 2019 , p. 2 et seqq.). The intention of the blockchain is the creation of a decentralized peer-topeer network. Peer-to-peer means that the communication takes place directly between the network nodes, thereby no central authority is required. Unlike conventional networks, the data is not stored on a single server, but instead each network node stores all information (Christidis \& Devetsikiotis, 2016, p. 2293; O'Leary, 2017, p. 138).

As illustrated in Figure 2, the traditional client/server model gives authority to a central server which then provides clients with information. Even though these centralized systems have performed well for many years, they have several vulnerabilities, such as the storage of all data in one spot, which attracts hacker attacks. In this context, major transaction and communication problems can be anticipated in the event of malfunctions (see Dwyer, 2017, p. 6; Filipova, 2018 , p. 78 et seq.). In contrast, the distributed ledger of a peer-to-peer technology allows each participant to obtain a local copy of the blockchain. Network participants can legitimize and verify transactions at any time. Consequently, not only the data storage is regulated locally but also the communication between the participants. As a result of the decentralized storage, the peer-to-peer network is considered as more efficient and resistant to hacker attacks by ensuring a higher level of reliability in contrast to centralized systems (Rosic, 2019, no page).

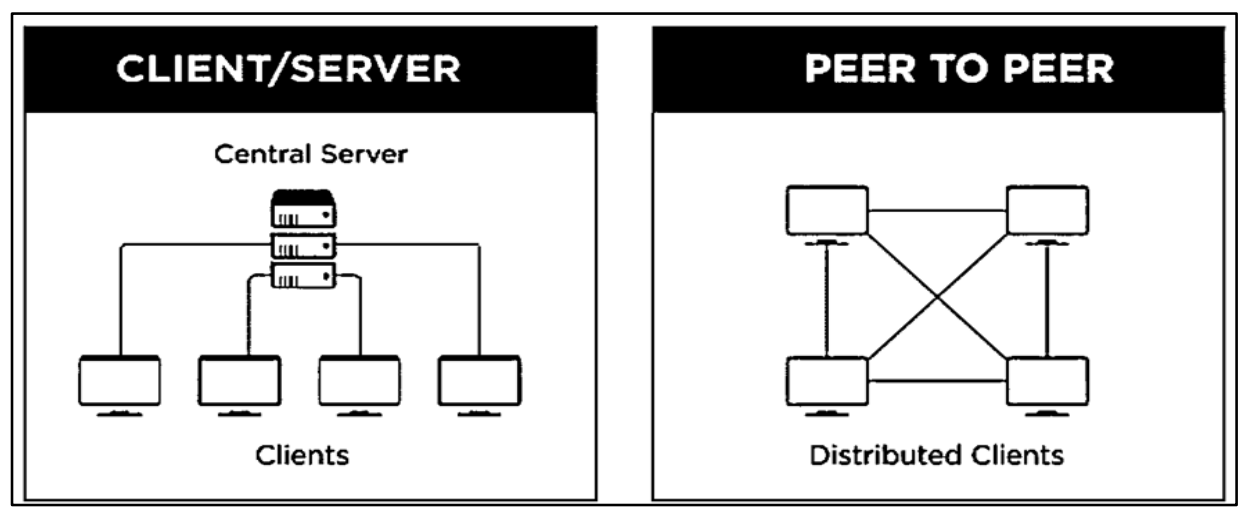

Figure 2. Client-Server Architecture vs. Peer-to-Peer-Network

Note. Own illustration after Lewis, 2015, no page; Dwyer, 2017, p. 16 
The following principles have been identified by the Harvard Business Review as the "five basic principles" of the blockchain technology and is illustrated in Figure 3:

\begin{tabular}{|c|c|}
\hline $\begin{array}{c}1 . \\
\text { Distributed Database: }\end{array}$ & $\begin{array}{l}\text { - Each party on a blockchain has access to the entire } \\
\text { database and its complete history. There is no central } \\
\text { control and every party can verify the records without an } \\
\text { intermediary. }\end{array}$ \\
\hline $\begin{array}{c}2 . \\
\text { Peer-To-Peer Transmission }\end{array}$ & $\begin{array}{l}\text { - Communication takes place directly between peers } \\
\text { instead through a central node. Each node stores and } \\
\text { forwards information to all other nodes. }\end{array}$ \\
\hline $\begin{array}{l}3 . \\
\text { Transparency with } \\
\text { Pseudonymity }\end{array}$ & $\begin{array}{l}\text { - Transactions are visible and transparent to anyone with } \\
\text { system access. Users can however remain anonymous or } \\
\text { provide proof of their identify. }\end{array}$ \\
\hline $\begin{array}{l}4 . \\
\text { Irreversibility of Records }\end{array}$ & $\begin{array}{l}\text { - Once a transaction is entered the records cannot be } \\
\text { altered. }\end{array}$ \\
\hline $\begin{array}{l}5 . \\
\text { Computational Logic }\end{array}$ & $\begin{array}{l}\text { - Users can set up algorithms and rules that automatically } \\
\text { trigger transactions between nodes. }\end{array}$ \\
\hline
\end{tabular}

Figure 3. The 5 Basic Principles of the Blockchain Technology

Note. Own Illustration based on Iansiti \& Lakhani, 2017, p. 5; Tapscott \& Tapscott, 2017, p. 3

\subsection{Basics of Smart Contracts}

A key emerging use case of blockchain technology involves "smart contracts" (see Crosby et al., 2016, p. 8; Rauscher \& Cupic, 2018, p. 1 et seqq.). According to different sources, smart contracts bear the potential to leverage the usefulness of blockchains on a truly meaningful scale (see Marino, 2015; Rosic, 2019). However, before the question "what are smart contracts?" can be answered, it is important to understand the definition of a contract. To shorten the definition phase, the basics function of a contract can be summarized as follows: A contract implies obligations and benefits. Any trade - as quid quo pro - must be mediated by some form of contract (Hart \& Holmstrm, 1986, p. 1). Lauslathi et al. describe a contract as a bilateral legal act which establishes rights and obligations for the parties to it (Lauslahti et al., 2017, p. 10).

Basically, smart contracts feature the same kind of agreement between different parties but unlike conventional contracts established by written words, speech or action; smart contracts are algorithmic, self-executing, and self-enforcing computer programs which can implement contract terms automatically (Lauslahti et al., 2017, p. 2). Marino explains that the blockchain is the ideal place to store such a contract, because of its immutability and its cryptographic security (Marino, 2015, no page).

The concept of smart contracts was first introduced by Nick Szabo in 1996 (Magazzeni et al. 2017 , p. 2 et seq.) and is therefore chronologically seen more major than the blockchain technology itself. Szabo explained the idea of smart contracts exemplary with the situation of a missing installment for a leased car: In case of an overdue payment, the smart contract automatically revokes the digital key to operate the car (Szabo, 1997 in Foroglou \& Tsilidou, 2015, p. 6). 
The special characteristic of smart contracts is that they remove the need for an intermediary to trust the execution of the contract. A trustless network is created, and the parties can transact even though they may not really trust each other (Christidis \& Devetsikiotis, 2016, p. 2292). The verification of the contractual conditions is realized through algorithms and subsequent contract terms, which are automatically executed without interventions of intermediaries. This comes along with a faster reconciliation between transacting parties (Christidis \& Devetsikiotis, 2016, p. 2292) and offers a high level of automation potential by replacing many human interactions.

According to several researchers, there are three elements of smart contracts that make them distinct: autonomy, self-sufficiency, and decentralization (Swan, 2015, p. 15; Anjum et al., 2017, p. 84).

\section{Blockchain in Practice - Opportunities \& Challenges}

\subsection{Use-Cases in General}

The following section provides a few blockchain and smart contract use-cases, explaining basic functionalities and advantages. These examples then serve as an inspiration to investigate in section 3.2 application areas in the finance domain.

According to the literature review, there are many examples of potential uses of blockchain technology, such as property records/smart property, banking/online payment, supply chain auditing, anti-money laundering, stock trading, crowdfunding, smart contracts, voting, and intellectual property (IP) rights (see Foroglou \& Tsilidou, 2015; Rosic, 2019; Zheng et al., 2019). In the following, a few use-cases are described in more detail.

An example by Christidis and Devetsikiotis illustrates the usefulness of blockchains in a supply chain setting. The situation is as follows: A container leaves the manufacturer's site, gets transported via railway to the neighboring port, then gets shipped to the destination port from where it gets transported again to the distributor's facilities until it reaches the retailer's site (see Christidis \& Devetsikiotis 2016, p. 2299).

This process involves several stakeholders and checks along with the transportation. In general, each participant maintains their own database to keep track of the asset, which they update unsynchronized based on individual inputs along the chain. A blockchain network may enable all stakeholders to track synchronically the asset from a shared database, where updates come with cryptographic verifiability and get automatically distributed along with the network (ibid.). Thereby an auditable trail of information is ensured, time is saved, and communication channels are optimized. The advantages become more evident when considering the high occurrence of problems that may arise in the analogous documentation process and in consideration of the expenditure of time required to inform all parties and clarify questions regarding the transportation status.

Another example given by Blockgeeks demonstrates the benefits of bypassing an intermediary and thereby enabling a peer-to-peer transaction: Today, a customer may decide to buy rail tickets on an app or the web, thereupon the credit card company charges a transaction fee to the customer and to the railway company. The blockchain technology meanwhile disconnects the intermediary and enables the customer and the railway company to transfer and store money within a peer-to-peer network. Subsequently, the entire transaction including the rail ticket is saved and added as a block to the blockchain, whereby the parties save credit card processing 
fees (Rosic, 2019, no page). Consequently, the blockchain has the potential to replace all processes and business models including middlemen and matchmaking platforms that previously charged fees for connecting transactions parties. In addition, this may also improve the data availability for the railway company in terms of big data analysis.

Swan refers to the code execution in a vending machine as a basic example to demonstrate the use of smart contracts. The vending machine behaves algorithmically and follows automatically the same instruction set every time in every case. "When you deposit money and make a selection, the item is released." A smart contract similarly executes the prespecified code without any further services (Swan, 2015, p. 16). As Lessig claims, "code is law" (Lessig, 1999 in Swan, 2015, p. 16). In this sense, the code will execute the transaction without room for interpretation and without the need of having a third party ensuring the correctness and completeness of the execution.

Nordgren et al. exemplary outline the potential usage of smart contracts in the insurance sector. In their example, insurance companies could set up a blockchain network and include their clients and care facilities to be members of the chain. The clients only see their own insurance information, which they can synchronously update for all parties with new information and in case of incidents, smart contracts can be used to execute payments automatically through the blockchain network (see Nordgren, 2019, p. 52).

\subsection{Opportunities \& Risks in Corporate Finance}

\subsubsection{Funding Innovation in the Blockchain Age - Initial Coin Offering}

Finance and accounting are the fields predicted to be most disrupted by blockchain technology (see Treleaven et al., 2017, McKinsey \& Company, 2018; Rosic, 2019). The following two sub-sections will introduce uses-cases in the financial context to discuss and outline opportunities and risks of this new technology.

A disruptive change can be assumed in the context of corporate funding. In this context, blockchain technology and smart contracts have been identified to be the core technology behind the initial coin offering (ICO) mechanism (see Hacker \& Thomale, 2018; Hahn, \& Wons 2018; Fenu et al. 2018). This new funding mechanism shows several parallels to the initial public offering (IPO) process. Both funding models sell rights on the public capital market to investors. According to Robinson, the public coin-offering has become the fastestgrowing capital market in the world. However, in terms of funding volume, ICOs are much smaller than IPOs. The median IPO proceeds in 2016 amounts USD 94,5 million compared to USD 6,4 million for ICOs (Robinson, 2018, p. 897).

Zetzsche et al. explain that investors who offer capital receive "coins/tokens" which represent a right of some kind (Zetzsche et al., 2018, p. 7 et seq.). The rights depend on the design of the token. They may include the right to receive a share of future earnings, to use a network or software applications, or the right to redeem the token for a commodity (see Stellar Develoment Foundation, 2017, p. 6).

What makes the ICO special is the direct distribution of coins/tokens to investors and thereby bypassing the bank as an intermediary. This is possible by using the blockchain technique and the functionality of smart contracts, which ensure the automatic execution of general contract conditions, which the parties have committed to, e.g. exchange of liquidity vs. token/coin (Boreiko \& Sahdev, 2018, p. 8 et seqq.). 
The advantages and disadvantages of these funding instruments stem from their divergences which are illustrated in Table 1.

Table 1.

Illustrative comparison of ICO vs. IPO

\begin{tabular}{|c|c|c|}
\hline Criteria & Initial Public Offerings (IPO) & Initial Coin Offerings (ICO) \\
\hline Stage & $\begin{array}{c}\text { More mature in terms of } \\
\text { product and business strategy }\end{array}$ & Seed/early stage e.g., start-ups \\
\hline Parties involved & $\begin{array}{c}\text { Issuer, lawyers, auditor and } \\
\text { investment bank }\end{array}$ & Issuer and platforms \\
\hline Investors & Institutional investors & $\begin{array}{l}\text { Peer-to-peer, crowd investors in } \\
\text { the internet }\end{array}$ \\
\hline Placement type & $\begin{array}{l}\text { Intermediated by investment } \\
\text { banks }\end{array}$ & $\begin{array}{c}\text { Direct placement and usage of } \\
\text { ICO platforms }\end{array}$ \\
\hline Technology & $\begin{array}{c}\text { Custody, clearing and } \\
\text { settlement systems }\end{array}$ & Blockchain based technology \\
\hline Regulation & $\begin{array}{l}\text { Highly regulated area, global } \\
\text { convergence of established } \\
\text { standards }\end{array}$ & Nascent stage, little guidance \\
\hline Offering document & Approved security prospectus & Primarily white paper \\
\hline Trading & $\begin{array}{l}\text { Active trading on established } \\
\text { exchanges, fiat currencies (e.g., } \\
\text { USD, EUR, HKD) }\end{array}$ & $\begin{array}{c}\text { Volatile trading on ICO } \\
\text { platform, tradeable through } \\
\text { cryptocurrencies }\end{array}$ \\
\hline Assets & $\begin{array}{l}\text { Different share types } \\
\text { representing ownership }\end{array}$ & $\begin{array}{l}\text { Tokens and underlying rights } \\
\text { are customized }\end{array}$ \\
\hline
\end{tabular}

Note. Own presentation based on: EY, 2017; OECD, 2019

Traditionally (before the ICO), the raising process for capital would start with angel investors in the early stages of a new business, later a reach out to venture capitalists until maturity of the company allows it to culminate in an IPO. As illustrated in the table, the traditional process depended on several intermediaries, such as investment bankers, exchange operators, auditors, and lawyers. Nowadays, the Blockchain changes this equation by enabling companies of any size to raise money in a peer-to-peer way (Tapscot \& Tapscot, 2017, p. 4). Major advantages can be achieved through the benefits of the blockchain technology, such as process automation and the reduction of intermediaries. The execution of the contract takes place without the assistance of contracting parties, thereby time is saved, but also the trusted intermediary can be dispensed, and financial resources can be saved. According to an article of PWC, the underwriter fee of an ICO amounts to approximately 4-7\% of the total issue volume that could then be saved (PWC, 2017, pp. 5-13).

On the other hand, the blockchain including smart contracts bear several risks given that for instance, the legal enforceability of smart contracts is limited (see Marino, 2015; Lauslathi et al. 2019). With reference to Filippi, work is being done to make the technical rules of smart contracts legally enforceable and binding to all parties (see Filippi, 2015), however, this may take time and until legal implementation is done, the process suffers several uncertainties. Christidis and Devetsikiotis suggest including a reference to the actual real-world contract into the smart contract to thereby increase the chances of legal enforceability (Christidis \& Devetsikiotis 2016, p. 2300). However, this may not solve all issues. What happens for instance 
in case of transaction errors, e.g. wrong code or a mistake in the wallet address? Today, there is no guarantee regarding the legal or economic maturity of the coin-offering company. In contrast, within an IPO the auditor guarantees a legal and economic maturity of the organization in form of a comprehensive due diligence assessment. The missing due diligence of an ICO may consequently lead to an inadequate compliance and management of financial resources. Another risk represents the lack of legislation regarding the legal requirement of whitepapers (see Zetzsche et al. 2018, p. 15 et seqq). Concerning the ICO process, a major disadvantage can be linked to the lack of experience. Due to the described, the BaFin highlights numerous legal and economic risks associated with the ICO process (see BaFin, 2017, no page).

\subsection{Blockchain in Auditing and Accounting - The Triple Entry Ledger}

A further disruptive change driven by the blockchain technology can be anticipated in the accounting and auditing domain. Gotthardt et al. explain that a major shortcoming of the current audit methodology is that transactions and accounts are verified using sampling. This means that not all transactions and accounts are actually verified (Gotthardt et al., 2019, p. 33), which gives room for corruption (see Simoyama et al. 2017).

Today, auditors can only give reasonable assurances as opposed to a full audit on the performance of the organization but with the blockchain technology, this shortcoming can be improved given that transactions in the blockchain are already validated by the transaction parties and approved by the consensus mechanism. As the timestamped and hashed data cannot be altered, auditors can better assess with an increased reliability the entire value chain including all transactions of the organization (Dai, 2017, p. 64 et seqq.). In this context, Dai provides a comprehensive analysis of the implications of blockchain technology in the field of accounting, auditing, and attestation (see Dai, 2017).

Interestingly, a close relationship of the blockchain technology and the accounting domain may already be assumed due to the common feature of the underlying blockchain functionality, which builds on the concept of traditional double-entry accounting systems (see Maurer, 2016, p. 82 et seqq.; Nordgren et al. 2019, p. 49). A blockchain-based bookkeeping system can fundamentally change the traditional booking system where both parties keep their own records of the event within their separated ledgers. Within the new blockchain system, all transactions are validated by both parties, and then the transaction is additionally recorded in an open and shared ledger, creating a "triple-entry ledger" (Fanning \& Centers, 2016, p. 57; Dai, 2017, p. 64 et seqq.). Thereby, all parties have harmonized information in real-time which comes along with several advantages, such as time-saving opportunities and the elimination of mistakes or fraud attempts (see Rückeshäuser, 2017, p. 87 et seqq.; Simoyama et al. 2017, p. 173). In a direct comparison, the traditional system is prone to error given that the records of transacting parties don't always match, this weakness can be eliminated. A blockchain ledger can enable all parties to track synchronically transactions from a shared database, where updates come with cryptographic verifiability and automatic transmission.

In view of this new digital environment, which is characterized as more transparent, it can be assumed that a main advantage in the field of accounting and auditing stem from more efficient data transfers, a sophisticated and secure data storage which comes along with more precise financial records and time-saving opportunities due to more effective controls by reducing at the same time even the risk of financial fraud. Thereby, the blockchain technology provides 
the opportunity to further close the "expectation gap", which is defined as the discrepancy between the expectations of stakeholders as to objectives and scope of the audit on the one hand and the informative value of the audit report and the relevant legal provisions on the other hand.

As Christidis and Devetsikiotis conclude, a complete autonomy is a double-edged sword (Christidis \& Devetsikiotis 2016, p. 2299). Despite promising opportunities for the blockchain technologies, there are also several risks and disadvantages to be considered. In this context also the limited scalability and lower transaction processing throughput, higher latencies, as well as questions regarding the privacy must be taken into account (Swan, 2015, p. 81 et seqq.; Christidis \& Devetsikiotis 2016, p. 2299; Florea, 2018, p. 1) next to the various other aspects which may not be known yet due to the limited expertise.

\section{Conclusion \& Outlook}

The given paper addressed in simple terms the essential features of the blockchain technology and the idea of smart contracts. Concerning the initially presented research question use-cases illustrated the functionality of the blockchain technology and smart contracts. In section 3.2 use-cases in finance have been described, such as the ICO process. It can be assumed that this new funding mechanism will fundamentally influence the public capital market and attract significantly the attention of ventures, investors, and policymakers. However, there are several uncertainties regarding technicities and legal aspects due to missing or little expertise. With regard to the second example, the blockchain application in the accounting and auditing domain has been introduced. In this context, it has been illustrated that the blockchain technology has a disruptive potential to fundamentally improve the double-entry accounting systems. However, these changes require plenty of time to be executed and moreover acceptance in the mindsets of the parties involved.

As blockchain promises to prevent fraud, increase trust, transparency and save time and money by eliminating intermediaries, it is one of the most promising technologies of the early years of the $21^{\text {st }}$ century. However, despite the noise, there are less detailed use-cases in corporate finance explaining where blockchain has changed already business processes. This has been outlined as well by Nordgren et al., who characterize the blockchain research to be in its infancy state (Nordgren, et al. 2019, p. 48). Insights of real-world evidence may further help practitioners and researchers to understand the opportunities and challenges in transforming business models to the blockchain technology. Regarding the changing environment, further investigation of how new technologies can support existing business will be useful to generate. These studies may also give explanations, how new processes can be used and embedded in existing structures, and what risks and limitations may arise. Finally, in this context, one of the most well-known theories in finance should be mentioned, which is the principal-agent theory. This theory deals with information asymmetries and trust in transactions. The blockchain technology may fundamentally influence the status-quo of this theoretical framework by influencing the current business setting and eventually offering solutions in matters of trust. Based on the described effects it can be recommended to review established theories in this future context. 


\section{References}

BaFin (2017): Initial Coin Offerings: Hohe Risiken für Verbraucher, https://www.bafin.de/SharedDocs/Veroeffentlichungen/DE/Fachartikel/2017/fa_bj_1711_I CO.html [accessed 2019-08-07, 20:30 CET]

Boreiko, D., \& Sahdev, N. K. (2018). To ico or not to ico-empirical analysis of initial coin offerings and token sales. Available at SSRN 3209180.

Christidis, K., \& Devetsikiotis, M. (2016). Blockchains and smart contracts for the internet of things. Ieee Access, 4, 2292-2303.

Crosby, M., Pattanayak, P., Verma, S., \& Kalyanaraman, V. (2016). Blockchain technology: Beyond bitcoin. Applied Innovation, 2(6-10), 71.

Dai, J. (2017). Three essays on audit technology: audit 4.0, blockchain, and audit app (Doctoral dissertation, Rutgers University-Graduate School-Newark).

De Filippi, P. (2015). Legal Framework for Crypto-Ledger Transactions.

Dwyer, G. P. (2017). Blockchain: a primer. The Most Important Concepts in Finance, Edward Elgar Publishing, 12-27.

Ernst \& Young (2018): IPO and ICO markets at a glance. https://www.ey.com /Publication/vwLUAssets/ey-ipo-and-ico-markets-at-a-glance/\$FILE/ey-ipo-and-icomarkets-at-a-glance.pdf [accessed 2019-06-22, 20:03 CET]

Fanning, K., \& Centers, D. P. (2016). Blockchain and its coming impact on financial services. Journal of Corporate Accounting \& Finance, 27(5), 53-57.

Fenu, G., Marchesi, L., Marchesi, M., \& Tonelli, R. (2018). The ICO phenomenon and its relationships with ethereum smart contract environment. In 2018 International Workshop on Blockchain Oriented Software Engineering (IWBOSE) (pp. 26-32). IEEE.

Filipova, N. (2018). Blockchain-an opportunity for developing new business models. Бизнес управление, (2 EN), 75-92.

Florea, B. C. (2018, June). Blockchain and Internet of Things data provider for smart applications. In 2018 7th Mediterranean Conference on Embedded Computing (MECO) (pp. 1-4). IEEE.

Foroglou, G., \& Tsilidou, A. L. (2015, May). Further applications of the blockchain. In 12th Student Conference on Managerial Science and Technology.

Gotthardt, M., Koivulaakso, D., Paksoy, O., Saramo, C., Eds. Martikainen M. and Lehner OM. (2019). Current State and Challenges in the Implementation of Robotic Process Automation and Artificial Intelligence in Accounting and Auditing. ACRN Oxford Journal of Finance and Risk Perspectives, 8(2019) Special Issue Digital Accounting, 31-46.

Gupta, S., \& Sadoghi, M. (2019). Blockchain Transaction Processing.

Hacker, P., \& Thomale, C. (2018). Crypto-securities regulation: Icos, token sales and cryptocurrencies under EU financial law. European Company and Financial Law Review, 15(4), 1-44. 
Hahn, C., \& Wons, A. (2018). Initial Coin Offering (ICO): Unternehmensfinanzierung auf Basis der Blockchain-Technologie. Springer-Verlag.

Hart, O. D., \& Holmstrm, B. (1986). The theory of contracts.

Iansiti, M., \& Lakhani, K. R. (2017). The truth about blockchain. Harvard Business Review, 95(1), 118-127.

Lauslahti, K., Mattila, J., \& Seppala, T. (2017). Smart Contracts-How will blockchain technology affect contractual practices?. Etla Reports, (68).

Lessig, L. (1999). Code is law. The Industry Standard, 18.

Lewis, A. (2015): A Gentle Introduction to Blockchain Technology, https://bitsonblocks.net/2015/09/09/gentle-introduction-blockchain-technology [accessed 2019-09-01, 19:20 CET]

Magazzeni, D., McBurney, P., \& Nash, W. (2017). Validation and verification of smart contracts: A research agenda. Computer, 50(9), 50-57.

Marino, B., (2017). Smart Contracts: The Next Big Blockchain Application https://tech.cornell.edu/news/smart-contracts-the-next-big-blockchain-application [accessed 2019-09-08, 15:20 CET]

Maurer, B. (2016). Re-risking in realtime. On possible futures for finance after the blockchain. Behemoth-A Journal on Civilisation, 9(2), 82-96.

McKinsey and Company (2018). Blockchain beyond the hype: What is the strategic business value? Retrieved from https:/www.mckinsey.com/business-functions/digitalmckinsey/our-insights/blockchain-beyond-the-hype-what-is-the-strategic-business-value [accessed 2019-09-08, 20:30 CET]

Nakamoto, S. (2008). Bitcoin: A peer-to-peer electronic cash system.

Nordgren, A., Weckström, E., Eds. Martikainen M. and Lehner OM. (2019). Blockchain in the Fields of Finance and Accounting: A Disruptive Technology or an Overhyped Phenomenon? ACRN Oxford Journal of Finance and Risk Perspectives, 8(2019) Special Issue Digital Accounting, 47-58

OECD (2019), Initial Coin Offerings (ICOs) for SME Financing. https://www.oecd.org /finance/initial-coin-offerings-for-sme-financing.htm [ac-cessed 2019-06-28, 17:30 CET]

O'Leary, D. E. (2017). Configuring blockchain architectures for transaction information in blockchain consortiums: The case of accounting and supply chain systems. Intelligent Systems in Accounting, Finance and Management, 24(4), 138-147.

Panetta, K. (2017). Top trends in the gartner hype cycle for emerging technologies, 2017. Smarter With Gartner, 5.

PricewaterhouseCoopers (2017): Considering an IPO to fuel your company's future? Insight into the costs of going public and being public. https://www.pwc.com/hu/hu/szolgaltatasok/ konyvvizsgalat/szamviteli-tanacsadas/kiadvanyok/cost_of_an_ipo_2017.pdf [accessed 2019-06-28, 17:30 CET] 
Rauscher, A., \& Cupic, Z. (2018). Blockchain bassierte Smart Contracts: Grundlagen, Prozessunterstützung und Bewertung.

Rosic, A. (2019): What is Blockchain Technology? A Step-by-Step Guide For Beginners: https://blockgeeks.com/guides/what-is-blockchain-technology/\#COMMENTS [accessed 2019-09-08, 20:30 CET]

Rückeshäuser, N. (2017). Do we really want blockchain-based accounting? Decentralized consensus as enabler of management override of internal controls.

Simoyama, F. D. O., Grigg, I., Bueno, R. L. P., \& Oliveira, L. C. D. (2017). Triple entry ledgers with blockchain for auditing. International Journal of Auditing Technology, 3(3), 163-183.

Stellar Development Foundation \& The Luxembourg House of Financial Technology (2017): Understanding Initial coin Offerings: technology, benefits, risks, and - 62 - regulations, https://www.lhoft.com/uploads/editor/files/news/WhitePaper.pdf [accessed 2019-08-11, 19:30 CET]

Swan, M. (2015). Blockchain: Blueprint for a new economy. " O'Reilly Media, Inc.".

Szabo, N. (1997). Formalizing and securing relationships on public networks. First Monday, 2(9).

Tapscott, A., \& Tapscott, D. (2017). How blockchain is changing finance. Harvard Business Review, 1(9), 2-5.

Treleaven, P., Brown, R. G., \& Yang, D. (2017). Blockchain technology in finance. Computer, 50(9), 14-17.

Underwood, S. (2016). Blockchain beyond bitcoin. Communications of the ACM, 59(11), 1517.

Zetzsche, D. A., Buckley, R. P., Arner, D. W., \& Föhr, L. (2017). The ICO Gold Rush: It's a scam, it's a bubble, it's a super challenge for regulators. University of Lux-embourg Law Working Paper, (11), 17-83.

Zheng, Z., Xie, S., Dai, H. N., Chen, X., \& Wang, H. (2018). Blockchain challenges and opportunities: A survey. International Journal of Web and Grid Services, 14(4), 352-375. 